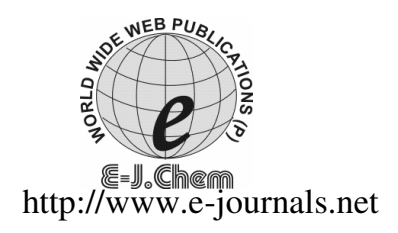

ISSN: 0973-4945; CODEN ECJHAO

E-Journal of Chemistry

2011, 8(2), 711-720

\title{
Dual-Wavelength Spectral Correction Method for Simultaneous Determination of V(IV) and V(V)
}

\author{
R. MIRZAJANI* and A. R KIASAT \\ Chemistry Department, College of Sciences \\ Shahid Chamran University, Ahvaz, Iran \\ rmirzajani@scu.ac.ir
}

Received 21 July 2010; Accepted 5 September 2010

\begin{abstract}
Simultaneous determination of $\mathrm{V}(\mathrm{IV})$ and $\mathrm{V}(\mathrm{V})$ was performed when the calibration matrix was obtained using beta-corrected spectral data. The method is based on the reaction between $\mathrm{V}(\mathrm{IV})$ and $\mathrm{V}(\mathrm{V})$ and 4-(2-pyridylazo)-resorcinol (PAR) as a ligand at $\mathrm{pH}$ 6. Using $\beta$-correction technique true absorbance of chelate produced can be calculated because the quantity of absorbance, which has related to the fraction of reagent that reacted with metal ion and has been subtracted when reagent applied as reference by this correction has compensated. The parameters controlling behavior of the system were investigated and optimum conditions selected. Calibration model was constructed based on absorption spectra in the 540-600 nm range for 25 different mixtures of $\mathrm{V}(\mathrm{IV})$ and $\mathrm{V}(\mathrm{V})$ in the concentration ranges of $0.10-4.00 \mu \mathrm{gmL}^{-1}$ of $\mathrm{V}(\mathrm{IV})$ and $0.10-5.00 \mu \mathrm{gmL}^{-1}$ of $\mathrm{V}(\mathrm{V})$. Applying this method to the analysis of mixtures of $\mathrm{V}(\mathrm{IV})$ and $\mathrm{V}(\mathrm{V})$ in waste water and soil samples with total relative standard error of less than $4.3 \%$ validated the proposed method.
\end{abstract}

Keywords: $\beta$-Correction, Partial least squares, $\mathrm{V}(\mathrm{IV}), \mathrm{V}(\mathrm{V})$, Simultaneous determination

\section{Introduction}

In recent years, increasing attention has been focused on pollution of the environment. Particular attention is being paid to the heavy metals, because of their irreversible effects on health. The determination of vanadium has received extensive attention because of its increasing importance in biological and environmental studies. Vanadium is one of the most important heavy metal pollutants. Its compounds can be highly toxic to human and animals and cause serious diseases. The industrial use of vanadium is widespread in the industry, catalyst industry, ceramic and electronic equipment. This element in trace amounts is an essential element for cell growth at $\mu \mathrm{g} \mathrm{L}^{-1}$ level, but can be toxic at higher concentrations. The toxicity of vanadium is dependent on its oxidation state ${ }^{1-4}$. 
$\mathrm{V}(\mathrm{V})$ is more toxic than other species but in many cases real samples contain both $\mathrm{V}(\mathrm{IV})$ and $\mathrm{V}(\mathrm{V})$. It has been noted that the environmental background levels of vanadium have been slowly rising because of the combustion of fossil fuels and marine products. Unlike organic pollutants, vanadium is not biodegradable and it may build up in certain ecosystems to the level, which may be toxic to living organisms ${ }^{5-6}$. Therefore, it is necessary to develop simple, sensitive, selective and rapid methods for speciation and quantitative determination of $\mathrm{V}(\mathrm{IV})$ and $\mathrm{V}(\mathrm{V})$ in real samples and it is an attractive topics for many researchers $^{7-14}$.

The quantification of multiple analytes in the same sample has developed into one of most interesting fields in chemical analysis and requires reliable and quick analytical methods. In this respect, the uses of multivariate calibration methods have grown rapidly and gaining popularity in the determination of metal concentrations in complex mixtures. The application of multivariate calibration techniques has resulted in improved applicability, precision and accuracy in multicomponent spectral analysis, even in cases where there is a considerable overlap of spectral features ${ }^{15-18}$. Data collected from complicated samples or in complicated processes contains variation from many sources and of several types. Preprocessing methods can be applied in such situations to enhance the relevant information to make resulting models simpler and easier to interpret. $\beta$-Correction spectrophotometery is applicable where both reagent and its complex with metal ion exhibit chromophoric properties ${ }^{19-23}$. This method is a dual-wavelength technique for determination of trace metals, which is different from ordinary spectrophotometry because it may eliminate the interference of excess of chromomeric reagent from its metal-colored solution to give the real absorbance of the chelate formed. Then the sensitivity, precision and accuracy by the dual-wavelength $\beta$-correction method are all higher than those for the ordinary one.

This is a novel method that used the power of PLS in noise reduction in one hand and the ability of correction method to remove the ligand contribution absorbance in the metal ion complexes. Generally the presence of the ligand absorbance in the spectral range of the complex increases the number of principle components needed to model the absorbance variation in the data matrix. But an application of correction method before applying PLS modeling drastically reduce the number of the principle components and hence reduces the complexity of the system. This is of interest for lower errors in the prediction steps of the analysis.

Simultaneous quantitative analysis of V(IV) and V(V) in the same sample is difficult to perform by classical spectrophotometric method due to overlapping spectra. Current efforts toward the development of new methods are focused primarily on increasing sensitivity and selectivity of the detection methods and simplifying the procedure by eliminating treatment and sampling steps. In this paper, a UV-vis specrtophotometric method is proposed for simultaneous determination of $\mathrm{V}(\mathrm{IV})$ and $\mathrm{V}(\mathrm{V})$ in real samples by $\beta$-correction technique true absorbance of chelate produced can be calculated and partial least squares (PLS) method can be used for the resolution of overlapping signals without prior separation. The method is based on the reaction between $\mathrm{V}(\mathrm{IV})$ and $\mathrm{V}(\mathrm{V})$ and PAR (Figure 1 ) at $\mathrm{pH} 6$.

\section{$\beta$-Correction theory}

In order to consider the general principle of $\beta$-correction spectrophotometry, the reaction of metal (M) with a colorant (L) can be expressed as follow ${ }^{24-25}$ :

$$
m M+n L \rightarrow r M L_{\gamma}+e L(\text { exess })
$$




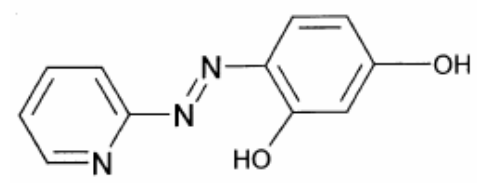

Figure 1. Chemical structure of 4-(2-pyridylazo)-resorcinol (PAR)

Where, $m$ and $n$ are the initial amount of the $\mathrm{M}$ and $\mathrm{L}$ added, respectively and $e$ is the excess concentration of $\mathrm{L}$. The term $\gamma$ represents the complexation ratio of $\mathrm{M}$ with $\mathrm{L}$. The following expression was developed for determination of real absorbance $A_{c}$ of metal (M) complex, $\mathrm{ML}_{\gamma}$ produced with a ligand $(\mathrm{L})$ :

$$
\begin{aligned}
A_{C} & =\frac{A_{\beta}}{1-\alpha \beta} \\
A_{\beta} & =\Delta A-\beta \Delta A^{\prime}
\end{aligned}
$$

Here, the term $\mathrm{A}_{\beta}$ was named $\beta$-correction absorbance, which was proportional to metal concentration. $\Delta \mathrm{A}$ and $\Delta \mathrm{A}^{\prime}$ are the absorbances of the reacted solution between $\mathrm{M}$ and $\mathrm{L}$ at wavelengths $\lambda_{1}$ and $\lambda_{2}$ against the reagent blank, respectively. The coefficients $\alpha$ and $\beta$ are named correction factors and they can be obtained as follows:

$$
\begin{gathered}
\alpha=\frac{\varepsilon_{M L \gamma}^{\lambda 1}}{\varepsilon_{M L \gamma}^{\lambda 2}} \\
\beta=\frac{\varepsilon_{L}^{\lambda 2}}{\varepsilon_{L}^{\lambda 1}}
\end{gathered}
$$

The terms $\varepsilon_{\mathrm{ML} \gamma}^{\lambda 1}, \varepsilon_{\mathrm{ML} \gamma}^{\lambda 2}, \varepsilon_{\mathrm{L}}^{\lambda 1}$ and $\varepsilon_{\mathrm{L}}^{\lambda 2}$ are the molar absorbtivities of ML $\gamma$ and L at wavelengths $\lambda_{1}$ and $\lambda_{2}$, respectively. $\lambda_{1}$ is absorption peak of reagent and $\lambda_{2}$ that of complex $\left(\lambda_{\max }\right)$. In fact with the help of $\beta$-correction technique true absorbance of chelate produced can be calculated because the quantity of absorbance, which has related to the fraction of reagent that reacted with metal ion and has been subtracted when reagent applied as reference by this correction has compensated.

\section{$\beta$-Correction multicomponent determination}

$\beta$-correction method can also apply to spectra of mixtures ${ }^{26}$. In a mixture, each of the metal will form a color complex with ligand and the fractional absorbance of each color compound can be calculated by the following correction equation.

$$
\begin{gathered}
\mathrm{A}_{\beta}=\sum_{\mathrm{j}=1}^{\mathrm{n}} \mathrm{a}_{\mathrm{ij}} \mathrm{x}_{\mathrm{j}}=\Delta \mathrm{A}_{\mathrm{i}}-\beta_{\mathrm{i}} \Delta \mathrm{A}^{\prime} \quad(\mathrm{i}=1,2, \ldots \mathrm{n}) \\
{\left[\begin{array}{cccc}
\mathrm{a}_{11} & \mathrm{a}_{12} & \ldots & \mathrm{a}_{1 \mathrm{n}} \\
\mathrm{a}_{21} & \mathrm{a}_{22} & \ldots & \mathrm{a}_{2 \mathrm{n}} \\
\ldots & \ldots & \ldots & \ldots \\
\mathrm{a}_{\mathrm{n} 1} & \mathrm{a}_{\mathrm{n} 2} & \ldots & \mathrm{a}_{\mathrm{nm}}
\end{array}\right]\left[\begin{array}{c}
\mathrm{or} \\
\mathrm{x}_{1} \\
\mathrm{x}_{2} \\
\ldots \\
\mathrm{x}_{\mathrm{n}}
\end{array}\right]=\left[\begin{array}{c}
\Delta \mathrm{A}_{1}-\beta_{1} \Delta \mathrm{A}^{\prime} \\
\Delta \mathrm{A}_{2}-\beta_{2} \Delta \mathrm{A}^{\prime} \\
\ldots \ldots \ldots \ldots \ldots \ldots \\
\Delta \mathrm{A}_{\mathrm{n}}-\beta_{\mathrm{n}} \Delta \mathrm{A}^{\prime}
\end{array}\right]}
\end{gathered}
$$




\section{Experimental}

UV Vis absorption spectra were recorded on a spectrophotometer model Citra 5, which equipped with a $1.00 \mathrm{~cm}$ path length quartz cells. Measurements of $\mathrm{pH}$ were made with a metrohm $780 \mathrm{pH}$ meter using a combined glass electrode. PLS algorithm was performed using chemometrics toolbox of MATLAB (version 6.12, Math Work, Inc.).

\section{Reagents and solutions}

All chemicals were of analytical reagent grade and were used directly without further purification (all from Merck). Triply distilled water was used to prepare buffer and reagent solutions. Stock solutions $\left(200 \mu \mathrm{gmL}^{-1}\right)$ of $\mathrm{V}(\mathrm{IV})$ and $\mathrm{V}(\mathrm{V})$ were prepared by dissolving $0.076 \mathrm{~g}$ of $\mathrm{VOSO}_{4} \cdot \mathrm{H}_{2} \mathrm{O}$ and $0.045 \mathrm{~g}$ of $\mathrm{NH}_{4} \mathrm{VO}_{3}$ in distilled water and diluting to $100 \mathrm{~mL}$ with distilled water. PAR solution $\left(5 \times 10^{-3} \mathrm{M}\right)$ was prepared by dissolving appropriate amount of the powder in distilled water and diluting with distilled water to $100 \mathrm{~mL}$. An acetate buffer (pH 6, 0.1 M of acetic acid) was also prepared.

\section{Sampling and preparation of wastewater samples}

Water samples were collected from wastewater from petrochemical industries. Each filtered environmental water sample $(1000 \mathrm{~mL})$ was evaporated nearly to dryness with a mixture of $1 \mathrm{~mL}$ of concentrated $\mathrm{H}_{2} \mathrm{SO}_{4}$ and $5 \mathrm{~mL}$ of concentration $\mathrm{HNO}_{3}$ in a fume cupboard and was then heated with $10 \mathrm{~mL}$ of de-ionized water in order to dissolve the salts. The solution was then cooled and neutralized. The resulting solution was then quantitatively transferred into a $25 \mathrm{~mL}$ calibrated flask and made up to the mark with de-ionized water. An aliquot $1 \mathrm{~mL}$ of this preconcentrated water sample was pipetted into a $10 \mathrm{~mL}$ calibrated flask and the vanadium content was determined as proposed procedure.

\section{Sampling and preparation of soil samples}

Approximately $0.25 \mathrm{~g}$ of soil from petrochemical industries field was first dissolved in a 10:1 mixture of concentrated $\mathrm{HF}(5 \mathrm{~mL})$ and concentrated $\mathrm{H}_{2} \mathrm{SO}_{4}(0.5 \mathrm{~mL})$ and heated till near dryness. Furthermore, $1 \mathrm{~mL}$ concentrated $\mathrm{HClO}_{4}$ and $2 \mathrm{~mL}$ concentrated $\mathrm{HF}$ were added and again the mixture was heated to near dryness. Finally, $1 \mathrm{~mL}$ concentrated $\mathrm{HClO}_{4}$ was added and the sample was evaporated until the appearance of white fumes. The residue was then dissolved in $5 \mathrm{~mL}$ of $6 \mathrm{M} \mathrm{HCl}$ and diluted to $50.0 \mathrm{~mL}$ with deionized water.

\section{Analytical procedure}

To a series of $10 \mathrm{~mL}$ volumetric flasks, $4 \mathrm{~mL}$ of PAR $(0.005 \mathrm{M})$ was added, to obtain a final concentration of $2 \times 10^{-3} \mathrm{M}$. Three milliliters of buffer solution $(\mathrm{pH}=6)$ then an appropriate amount of each metal ion containing 10-40 $\mu \mathrm{g}$ of $\mathrm{V}(\mathrm{IV})$ and $10-50 \mu \mathrm{g}$ of $\mathrm{V}(\mathrm{V})$ were added and the solutions were made up to the mark with distilled water. Excess concentration of reagent has been applied to ensure quantitative formation of the complexes in the whole range of determination. The spectral corrected data obtained by proposed method were processed by PLS algorithm for simultaneous determination of V(IV) and V(V) ions.

\section{Results and Discussion}

Assay conditions such as $\mathrm{pH}$ and mole ratios were investigated for optimization. The $\mathrm{pH}$ of working solutions is an important analytical factor for spectrophotometric simultaneous determination of metal ions to improve sensitivity and also to provide less spectral overlapping. The influence of $\mathrm{pH}$ on the spectrum of each complex at a constant concentration of metal ion was studied from $\mathrm{pH}$ 2-9 (Figure 2). The reaction between V(IV) and $\mathrm{V}(\mathrm{V})$ with PAR was sensitive at $\mathrm{pH}$, at which the absorbances for both of the complexes 
were high while the absorbance of PAR was low and spectra overlapping is minimum. Therefore, $\mathrm{pH} 6$ was selected as the optimum value. The effect of time on the completeness of reaction was studied. The two reactions formation for V(IV)-PAR and V(V)-PAR complexes, were completed after mixing at room temperature.

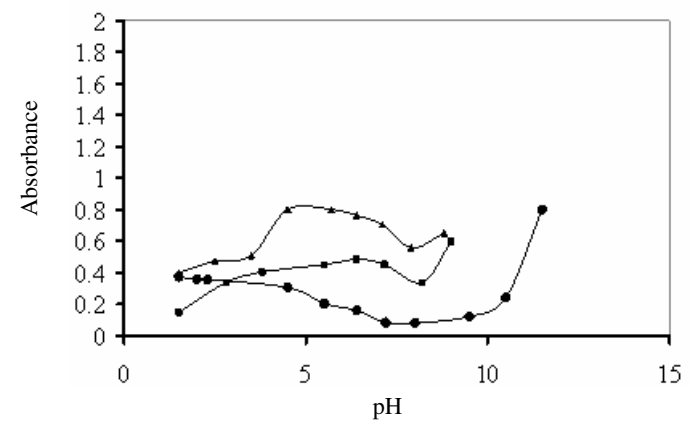

Figure 2. Effect of $\mathrm{pH}$ on change in absorbance, $2.0 \times 10^{-4} \mathrm{M}$ of PAR $(\bullet), \mathrm{V}(\mathrm{IV})-\mathrm{PAR}$ and $\mathrm{V}(\mathrm{V})$-PAR $(\boldsymbol{\Delta})$ at $3.0 \mu \mathrm{g} \mathrm{mL}^{-1}$ of $\mathrm{V}(\mathrm{IV})-\mathrm{PAR}$ and $2.0 \mu \mathrm{g} \mathrm{mL} \mathrm{L}^{-1}$ of $\mathrm{V}(\mathrm{V})$-PAR

To study the stoichiometry of the reactions, mole ratio (mole of metal ion/mole of ligand) method was applied for each complex at a constant concentration of the ligand (PAR $\left.6.0 \times 10^{-5} \mathrm{M}\right)$ and varying concentration of each metal ion. The results revealed that at $\mathrm{pH}=6$, both $\mathrm{V}(\mathrm{IV})$ and $\mathrm{V}(\mathrm{V})$ react with PAR in, (1:1) mole ratio. Therefore, an excess concentration of reagent has been chosen to ensure quantitative formation of the complexes in 1:1 mole ratio.

\section{Absorption spectra}

The absorption spectra of free PAR and its complexes with $\mathrm{V}(\mathrm{IV})$ and $\mathrm{V}(\mathrm{V})$ were recorded at $\mathrm{pH} 6$ and shown in Figure 3. In this Figure the interference of reagent spectra on the spectrum of both complexes is obvious. Because of the spectral overlapping of V (IV)-PAR and $\mathrm{V}(\mathrm{V})$-PAR complexes, it is difficult by conventional method to obtain an accurate measurement of each of the ions in mixtures. The reaction between $V(I V)$ and $V(V)$ with PAR was sensitive at $\mathrm{pH} 6$, over this condition absorption peak of the V(IV)-PAR complex was located at $555 \mathrm{~nm}$ and that of $\mathrm{V}(\mathrm{V})-\mathrm{PAR}$ complex at $560 \mathrm{~nm}$ (against reagent blank reference), but that of PAR at $525 \mathrm{~nm}$. These three wavelengths, such that the positive and negative absorbances approach the maximum, were selected for correction coefficients.

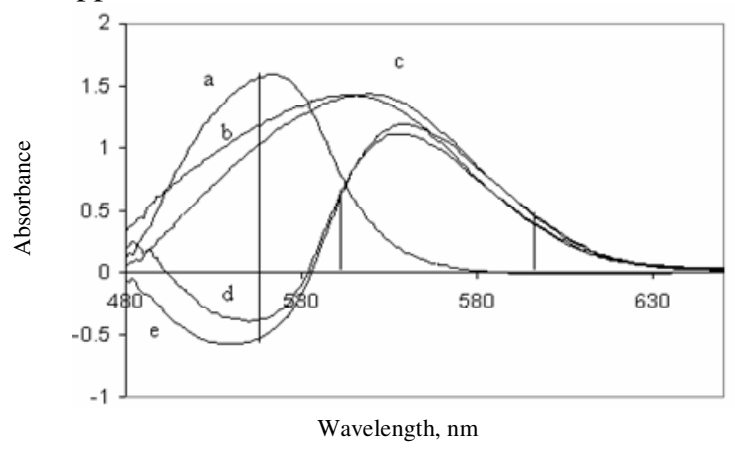

Figure 3. Absorption spectra of PAR,V(IV)-PAR and V(V)-PAR, curve (a) reagent blank (reference, water), (b) V(IV)-PAR (reference, water), (c) V(V)-PAR (reference, water), (d) PAR, V(IV)-PAR (reagent, reference) and (e) V(V)-PAR (reagent reference), curves for $3 \mu \mathrm{gmL}^{-1}$ of $\mathrm{V}(\mathrm{IV})$ and $3 \mu \mathrm{gmL}^{-1}$ of $\mathrm{V}(\mathrm{V})$ complexes and $2 \times 10^{-4} \mathrm{M}$ of PAR 
From curve "a", the correction coefficient was calculated to be $\beta=0.84$ at $555 \mathrm{~nm}$ and $\beta=0.417$ at $560 \mathrm{~nm}$ and from curves "b" and "c", the correction coefficients were calculated to be $\alpha_{555}=1.07$ and $\alpha_{560}=0.726$ for $\mathrm{V}(\mathrm{IV})$ and $\mathrm{V}(\mathrm{V})$, respectively. $\beta$-Corrected absorbances were calculated using these coefficients and Eqs. (1) and (2).

\section{Individual determination}

Over this condition absorption to find the linear dynamic range of each component, individual calibration graph were obtained. The absorption spectra were recorded over 540-600 at $1 \mathrm{~nm}$ intervals against a reagent blank. This spectral region was selected for analysis, because this is the zone with the maximum spectral information from the mixture components of interest. Under optimum conditions, linear range for each metal ion was determined by plotting the absorbances at its $\lambda_{\max }$ versus sample concentration. Linear equations are $\mathrm{A}=0.4307+$ $0.0931 \mathrm{C}_{i}$ for $\mathrm{V}(\mathrm{IV}),\left(\mathrm{r}^{2}=0.9992\right)$ and $\mathrm{A}=0.3515+0.082 \mathrm{C}_{i}$ for $\mathrm{V}(\mathrm{V})\left(\mathrm{r}^{2}=0.9983\right)$, (where $\mathrm{C}_{\mathrm{i}}$ is in $\left.\mu \mathrm{gmL}^{-1}\right)$.The calibration covers concentrations between $0.10-5.6 \mu \mathrm{gmL}^{-1}$ for $\mathrm{V}(\mathrm{IV})$ and $0.10-6.3 \mu \mathrm{gmL}^{-1}$ for $\mathrm{V}(\mathrm{V})$. The limits of detection ${ }^{27} 0.09$ and $0.1 \mu \mathrm{gmL}^{-1}$ for $\mathrm{V}(\mathrm{IV})$ and $\mathrm{V}(\mathrm{V})$, respectively, were calculated according to calibration lines characteristics.

\section{Multivariate calibration with spectral correction matrix}

\section{Design of input matrix}

The first step in simultaneous determination of different species by multivariate methods involves constructing the calibration set for binary mixtures of them. In this work, we performed the calibration with the $\beta$-correction data. The multivariate calibration requires a careful experimental design of the standard composition of calibration set to provide the best predictions. In order to select the mixtures that provide more information using a few experimental trials from calibration set, the training matrix was constructed as a full factorial design in the variables that spanned the investigated calibration space. Five level were chosen for each of component concentration in a full factorial design ${ }^{27}$ and $5^{2}$ objects were obtained in the assigned matrix (Table 1). Twenty-five binary mixtures were selected as the calibration set.

Table 1. Concentration of the calibration set for binary mixtures of V(IV) and V(V) $\mu \mathrm{gmL}^{-1}$

\begin{tabular}{cccc}
\hline $\mathrm{V}(\mathrm{IV})$ & $\mathrm{V}(\mathrm{V})$ & $\mathrm{V}(\mathrm{IV})$ & $\mathrm{V}(\mathrm{V})$ \\
\hline 0.10 & 0.10 & 2.66 & 3.95 \\
0.10 & 1.83 & 2.66 & 5.00 \\
0.10 & 2.70 & 3.27 & 0.10 \\
0.10 & 3.95 & 3.27 & 1.83 \\
0.10 & 5.00 & 3.27 & 2.70 \\
1.56 & 0.10 & 3.27 & 3.95 \\
1.56 & 1.83 & 3.27 & 5.00 \\
1.56 & 2.70 & 4.00 & 0.10 \\
1.56 & 3.95 & 4.00 & 1.83 \\
1.56 & 5.00 & 4.00 & 2.70 \\
2.66 & 0.10 & 4.00 & 3.95 \\
2.66 & 1.83 & 4.00 & 5.00 \\
2.66 & 2.70 & & \\
\hline
\end{tabular}

Training set of $\mathrm{V}(\mathrm{IV})$ and $\mathrm{V}(\mathrm{V})$ ions in calibration set were between $0.1-4.0 \mu \mathrm{g} \cdot \mathrm{mL}^{-1}$ of $\mathrm{V}(\mathrm{IV})$ and 0.11-5.0 $\mu \mathrm{g} . \mathrm{mL}^{-1}$ of V(V). In order to constructed PLS model a prediction set was prepared involve 20 synthetic test samples. The prediction set was randomly designed. Calibration set and prediction sets were used for construction of PLS model and the independent validation set was used to evaluate the quality of the model. 


\section{Data processing and model building}

The PLS technique is a typical full-spectrum method, more powerful than the ones based on measurement at only one wavelength such as direct spectrophotometry, because the simultaneous inclusion of multiple spectral intensities can greatly improve the precision and applicability of quantitative spectral analysis of mixtures. This method is very useful in the resolution of overlapping signals.

The concentration ranges for simultaneous determination were chosen so that the absorbances obtained for all standard solutions were not greater than 2.0. So training set of $\mathrm{V}(\mathrm{IV})$ and $\mathrm{V}(\mathrm{V})$ ions in calibration set were between 0.10 and $4.00 \mu \mathrm{gmL}^{-1}$ of $\mathrm{V}(\mathrm{V})$ and 0.10 and $5.00 \mu \mathrm{gmL}^{-1}$ of $\mathrm{V}(\mathrm{V})$. Data matrix was constructed with a group of wavelengths includes absorbances in the range of 540-600 nm which is included $\lambda_{\max }$ of both V(IV) and $\mathrm{V}(\mathrm{V})$ and a second group which contain just $\lambda_{\max }$ of ligand that is fixed in all calculations. These groups are shown in Figure 3. Correction coefficients and correction factors were calculated at these wavelengths. Then the values of $\beta$-corrected absorbances, $A_{\beta}$, were calculated using these coefficients and Eqs. (1) and (2). Finally, data matrix was constructed using these spectral correction data and Eqs. (5) and (6). $\beta$-Correction technique is used as preprocessing step on conventional spectral data in a constant $\lambda_{0}$ which is $\lambda_{\max }$ of ligand for all wavelengths in the first selected group $\lambda_{i}$ varied and spectral correction matrix was established. Finally the digitized absorbance of calibration mixtures was gathered in a $25 \times 60$ data matrix $(Y)$ and absorbances of prediction matrix were collected in a $20 \times 60$ data matrix $\left(Y_{\text {un }}\right)$. Also a vector of concentration of each species was made $(c)$ contain concentration of $\mathrm{V}(\mathrm{IV})$ or $\mathrm{V}(\mathrm{V})$ in binary mixtures of calibration and prediction set.

The selection of the number of factors used in the calibration with PLS is very important for achieving the best prediction. As a first approach, the number of factors was estimated by cross-validation method, leaving out one sample at a time and plotting the prediction residual sum of squares (PRESS) versus the number of factors for each individual component. A PRESS value for each number of factors was calculated by comparing the predicted concentration of compounds in each sample with known concentration of compounds in standard solutions. The PRESS values provide a measure of how well the training set is predicting the concentration for each number of factors. For finding best model with fewest numbers of factors, the $F$-statistic was used to carry out the significance determination $^{28}$. In this way, 4 and 3 factors were selected as optimum for $\mathrm{V}(\mathrm{IV})$ and $\mathrm{V}(\mathrm{V})$ respectively in Figure 4.

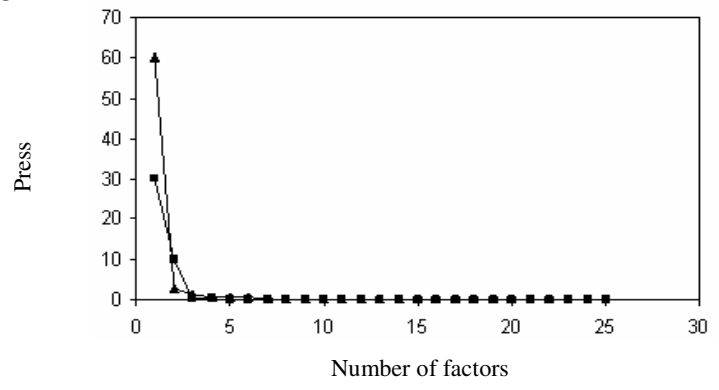

Figure 4. Plot of PRESS against the number of factors for ( $\boldsymbol{\bullet}) \mathrm{V}(\mathrm{IV})$ and $(\boldsymbol{\Delta}) \mathrm{V}(\mathrm{V})$.

PRESS obtained by optimizing model is shown. In order to investigate prediction ability of model and to validate proposed methods for simultaneous determination of $\mathrm{V}(\mathrm{IV})$ and $\mathrm{V}(\mathrm{V})$ some parameters were selected, the root-mean-square errors of prediction (RMSEP) 
can be used as fitness function. Prediction error of a single component in the mixture was calculated as the relative standard error (RSE) of the prediction concentration, Statistical parameters obtained for proposed method are all satisfactory (Table $2 \& 3$ ). The root-meansquare error (RMSE) of prediction is defined as follows ${ }^{29}$ :

$$
R M S E=\left[\frac{\sum_{s=1}^{r} \sum_{i=1}^{n}\left(\left(t_{s i}-y_{s i}\right) / t_{s i}\right)^{2}}{r n}\right]^{1 / 2}
$$

Table 2. Statistical parameters of optimization model

\begin{tabular}{cccccc}
\hline Species & PRESS & No. of factor & RSE, \% & RMSEP & $\mathrm{R}^{2}$ \\
\hline V(IV) & 0.07 & 4 & 1.50 & 0.026 & 0.9875 \\
V(V) & 0.13 & 3 & 2.08 & 0.047 & 0.9943 \\
\hline
\end{tabular}

Table 3. Composition of validation set, their results obtained by suggested method and $\mu \mathrm{gmL}^{-1}$

\begin{tabular}{cccc}
\hline \multicolumn{2}{c}{$\mathrm{V}(\mathrm{IV})$} & \multicolumn{2}{c}{$\mathrm{V}(\mathrm{V})$} \\
\hline Actual & Found & Actual & Found \\
0.60 & 0.66 & 0.15 & 0.12 \\
1.70 & 1.78 & 0.98 & 1.18 \\
2.20 & 2.02 & 1.33 & 1.27 \\
3.33 & 3.30 & 3.59 & 3.70 \\
0.20 & 0.22 & 4.19 & 4.25 \\
4.00 & 3.95 & 5.00 & 5.21 \\
R.S.E. $(\%)$ & 3.62 & & 4.20 \\
${ }^{\mathrm{a}}$ RSSPV & 0.08 & & 0.13 \\
\hline
\end{tabular}

a: RMSEPv is root-mean-square error for validation

Both summations in the above equation run over all $r$ input objects of the test set and over all $\mathrm{n}$ output variables. The RMSE value measures how good output $\mathrm{y}_{\mathrm{s}}$ values are in comparison with the target values $t_{s}$. The aim of any training is to reach as smallest RMSE values as possible in the shortest possible time. Also the prediction error of a single component in the mixture was calculated as the relative standard error (RSE) of the prediction concentration $^{30}$,

$$
\operatorname{RSE}(\%)=100 \times\left(\sum_{\mathrm{j}=1}^{\mathrm{N}}\left(\hat{\mathrm{C}}_{\mathrm{j}}-\mathrm{C}_{\mathrm{j}}\right)^{2} / \sum_{\mathrm{j}=1}^{\mathrm{N}}\left(\mathrm{C}_{\mathrm{j}}\right)^{2}\right)^{1 / 2}
$$

Where $\mathrm{N}$ is the number of samples, $\mathrm{C}_{\mathrm{j}}$ is the concentration of the component in the $\mathrm{j}^{\text {th }}$ mixture and $\hat{\mathrm{C}}_{\mathrm{j}}$ is the estimated concentration. The low RMSE and RSE were obtained indicate that the networks used, can process $\beta$-correction spectral data and model the complex relationship between the concentration of ions and corrected absorbance in the wider ranges. The reasonable relative standard errors for each analyte in both set indicate the accuracy of the proposed method.

\section{Application to the real samples}

In order to test the applicability in the presence of matrix interference the proposed method was applied in a variety of matrix compositions. $\mathrm{V}(\mathrm{IV})$ and $\mathrm{V}(\mathrm{V})$ were added to soil and waste water samples which showed negative test for vanadium. Several spiked samples were prepared by adding aliquots of $\mathrm{V}(\mathrm{IV})$ and $\mathrm{V}(\mathrm{V})$ solutions to industrial waste water and soil sample and effect of matrix and interfering ions were investigated. The results of prediction 
are summarized in Table 4. The good agreement between these results and known values indicates the successful applicability of proposed method for simultaneous determination of $\mathrm{V}(\mathrm{IV})$ and $\mathrm{V}(\mathrm{V})$ in real samples.

Table 4. Estimated and actual concentration of $\mathrm{V}(\mathrm{IV})$ and $\mathrm{V}(\mathrm{V})$ in environmental water samples

\begin{tabular}{ccccc}
\hline \multirow{2}{*}{ Sample } & \multicolumn{2}{c}{ Added, $\mu \mathrm{g} \mathrm{mL}^{-1}$} & \multicolumn{2}{c}{ Found, $\mu \mathrm{g} \mathrm{mL}{ }^{-1}$} \\
\cline { 2 - 5 } & $\mathrm{V}(\mathrm{IV})$ & $\mathrm{V}(\mathrm{V})$ & $\mathrm{V}(\mathrm{IV})$ & $\mathrm{V}(\mathrm{V})$ \\
\hline \multirow{3}{*}{ Wastewater } & 0.10 & 1.20 & $0.11(2.43)^{\mathrm{a}}$ & $1.33(2.43)$ \\
& 0.50 & 2.00 & $0.54(2.43)$ & $2.00(2.43)$ \\
& 1.00 & 3.50 & $1.1(2.43)$ & $3.56(2.23)$ \\
& 3.00 & 4.50 & $3.19(3.57)$ & $4.57(2.35)$ \\
Soil sample & 0.70 & 2.00 & $0.73(2.43)$ & $2.06(2.43)$ \\
& 4.00 & 4.50 & $4.01(3.28)$ & $4.64(3.28)$ \\
& 3.20 & 0.50 & $3.23(1.79)$ & $0.53(1.79)$ \\
& 1.80 & 2.26 & $1.91(3.11)$ & $2.47(2.23)$ \\
& 1.00 & 1.00 & $0.94(3.11)$ & $0.94(3.11)$ \\
\hline
\end{tabular}

${ }^{a}$ Relative standard error $(n=3)$

\section{Interference study}

The influence of various species on the absorbance of a solution mixture containing $4 \mu \mathrm{g} \cdot \mathrm{mL}^{-1}$ of $\mathrm{V}(\mathrm{IV})$ and $4 \mu \mathrm{g} \cdot \mathrm{mL}^{-1}$ of $\mathrm{V}(\mathrm{V})$ was investigated. An ion was considered as interference when its presence produced a variation in the absorbance of the sample greater than $5 \%$. This increment of absorbance was evaluated at two wavelengths, 555 and 560 (corresponding to the maximum absorption of $\mathrm{V}(\mathrm{IV})$ and $\mathrm{V}(\mathrm{V})$ complexes, respectively), in order to establish the different effects of the interfering ions on each analyte. Among the interfering ions tested $\mathrm{Tl}^{+}, \mathrm{Mo}^{6+}, \mathrm{C}_{2} \mathrm{O}_{4}{ }^{2-}, \mathrm{Ag}^{+}, \mathrm{Hg}_{2}{ }^{2+}, \mathrm{Tl}^{3}+, \mathrm{Cr}^{3+}, \mathrm{SO}_{4}{ }^{2-}$, $\mathrm{Na}^{+}, \mathrm{K}^{+}, \mathrm{CH} 3 \mathrm{COO}^{-}, \mathrm{NO}_{3}^{-}, \mathrm{IO}_{3}^{-}$and $\mathrm{Br}^{-}$did not interfere at concentrations 1000 times higher than those of the analytes and $\mathrm{Cu}^{2+}, \mathrm{Zn}^{2+}, \mathrm{Ni}^{2+}$ and $\mathrm{Co}^{2+}$ did not interfere at concentrations 50 times higher than those of the analytes. Fe(III) showed interference for both analytes at concentrations 20 times higher than that of analyte. Fe(III) ion could easily be masked by sodium dithionite.

\section{Conclusion}

Application of PLS method on the $\beta$-corrected date for simultaneous determination of $\mathrm{V}(\mathrm{IV})$ and $\mathrm{V}(\mathrm{V})$ as a complex system with high overlapping is an effective and accurate way. PLS modeling using a calibration matrix constructed with $\beta$-correction absorption has been successfully applied to simultaneous analysis of these metal ions in real samples. There is no need to know the exact form of the analytical function on which the model should be built also it requires no complex pretreatment or chromatographic separations of the samples containing analytes. This technique is simple, fast and affordable with high sensitivity, precision and accuracy for simultaneous determination of $\mathrm{V}(\mathrm{IV})$ and $\mathrm{V}(\mathrm{V})$.

\section{Acknowledgment}

The authors gratefully acknowledge the support to this work by Shahid Chamran University Research Council. 


\section{References}

1. Chen Z L and Owens G, Anal Chim Acta, 2008, 607(1), 1-14.

2. Filik H, Yanaz Z and Apak R, Anal Chim Acta, 2008, 620(1-2), 27-33.

3. Panichev N, Mandiwana K, Moema D, Molatlhegi R and Ngobeni P, J Hazard Mater., 2006, A137, 649-653.

4. Mandiwana K L and Panichev N, J Hazard Mater., 2009, 170(2-3), 1260-1263

5. Ruedas Rama M J, Ruiz Medina A and Molina A D, Talanta, 2005, 66, 1333-1339.

6. $\quad$ Qin W, Zhang Z and Zhang C, Analyst, 1997, 122, 685-688.

7. He X, Tubino M and Rossi AV, Anal Chim Acta, 1999, 389, 275-280.

8. Jarosz M and Oszwaldowski S, Chem Anal (Warsaw), 1993, 38, 109-115.

9. Abbaspour A and Mirzajani R, Talanta, 2004, 64(2), 435-441.

10. Jamaluddin Ahmed M and Banoo S, Talanta, 1999, 48(5), 1085-1094

11. Nukatsuka I, Shimizu Y and Ohzeki K, Anal Sci., 2002, 18, 1009-1014.

12. Melwanki M B, Seetharamappa J and Masti S P, Anal Sci., 2001, 17, 979-982.

13. Oszwaldowski S and Jarosz M, Microchim Acta, 1997, 126, 241-249.

14. Ensafi A A, Amini M K and Mazloum M, Anal Lett., 1999, 32,1927.

15. Safavi A, Abdollahi H, Sedaghatpour F and Zeinali S, Anal Chim Acta, 2000, 409, 275-282.

16. Rezaei B, Ensafi A A and Shandizi F, Microchem J., 2001, 70, 35.

17. Silva E L, Roldan P S and Giné M F, J Hazard Mater., 2009, 171, 1133-1138.

18. Wang D and Sañudo-Wilhelmy S A, Marine Chem., 2008, 112, 72-80.

19. Gao H W and Yu L Q, J Anal Chem., 2000, 55(9), 870-873.

20. Gao H W and Zhang P F, J Anal Chem., 2000, 55(8), 737-740.

21. Abbaspour A and Baramakeh L, Talanta, 2005, 65(3), 692-699

22. Abbaspour A and Baramakeh L, Talanta, 2002, 57(4), 807-812.

23. Gao H W, Li Y C and Ye Q S, Bull Korean Chem Soc., 2001, 22, 565.

24. Gao H W, Armenian Chem J., 1998, 51, 21.

25. Gao H W, Spectrochimica Acta Part A, 1995, 51, 1379-1384.

26. Gao H W, Chine Chem Lett., 2000, 11, 893-894.

27. Miller J C and Miller J N, Statistics and Chemometrics for Analytical Chemistry, $4^{\text {th }}$ Ed., Prentice-Hall, UK, 2000.

28. Martens H and Naes T, Multivariate Calibration, Wiley, New York, 1991.

29. Ariffin S and Karim A, Eur J Sci Res., 2009, 36(4), 513-520.

30. Safavi A, Abdollahi H and Mirzajani R, Spectrochimica Acta Part A, 2006, 63(1), 196-199. 


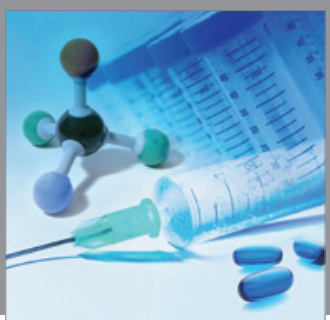

International Journal of

Medicinal Chemistry

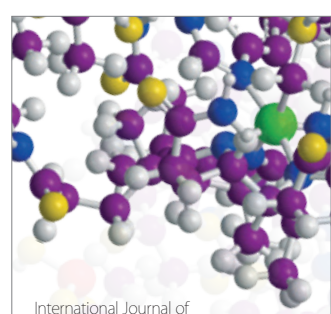

Carbohydrate Chemistry

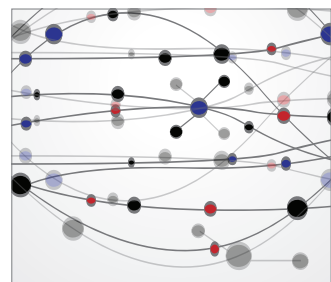

The Scientific World Journal
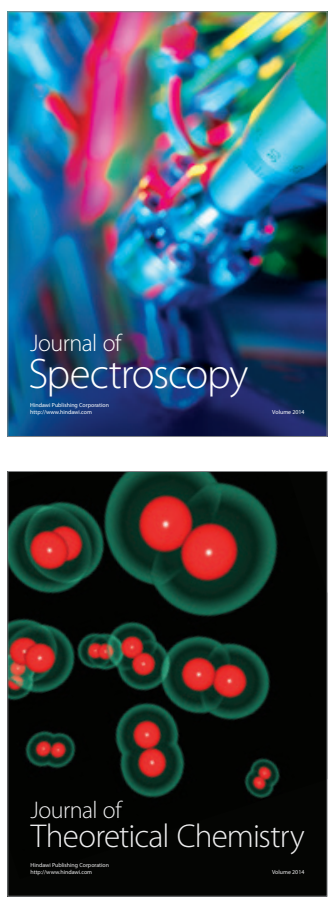
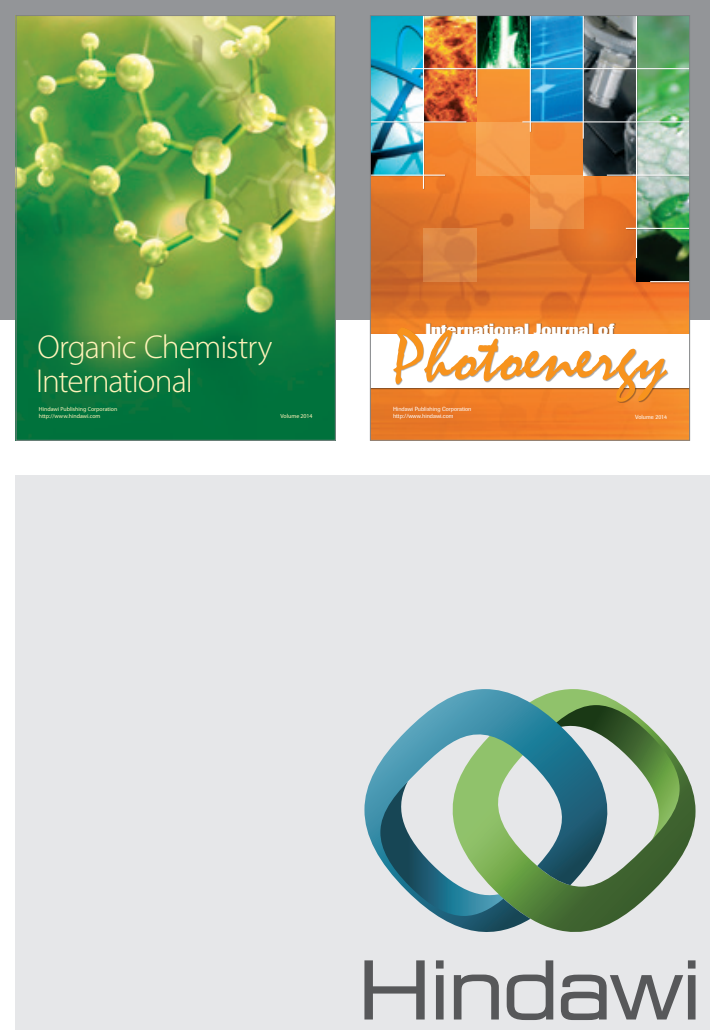

Submit your manuscripts at

http://www.hindawi.com
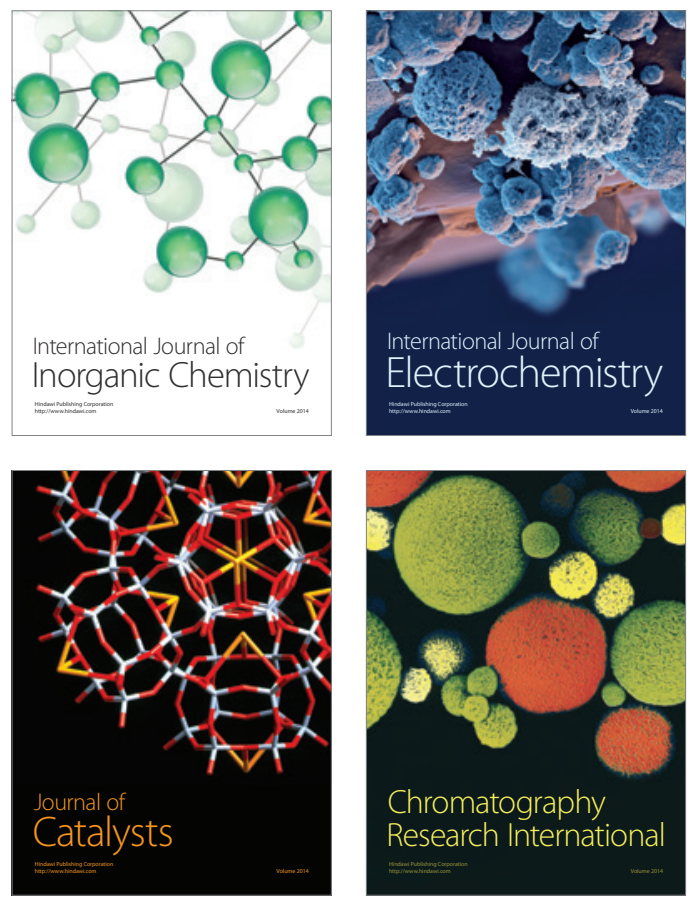
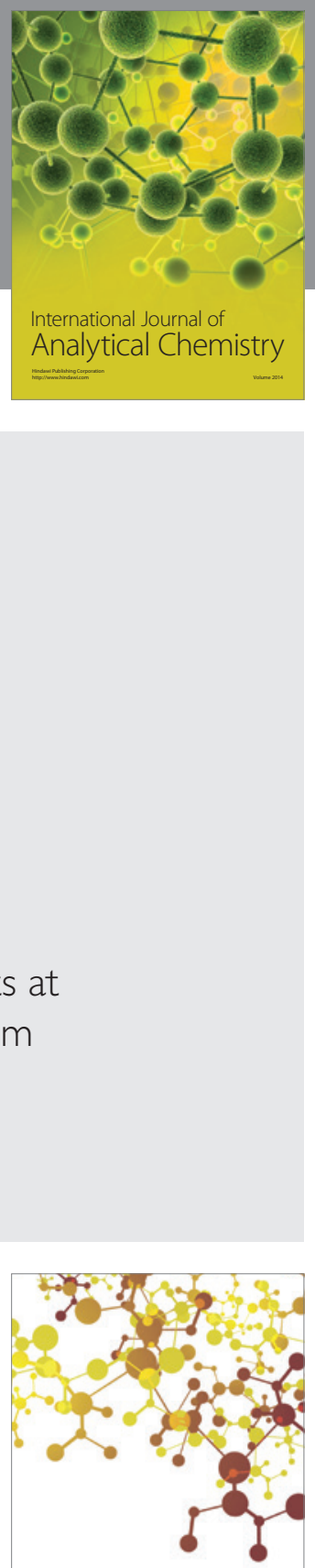

Journal of

Applied Chemistry
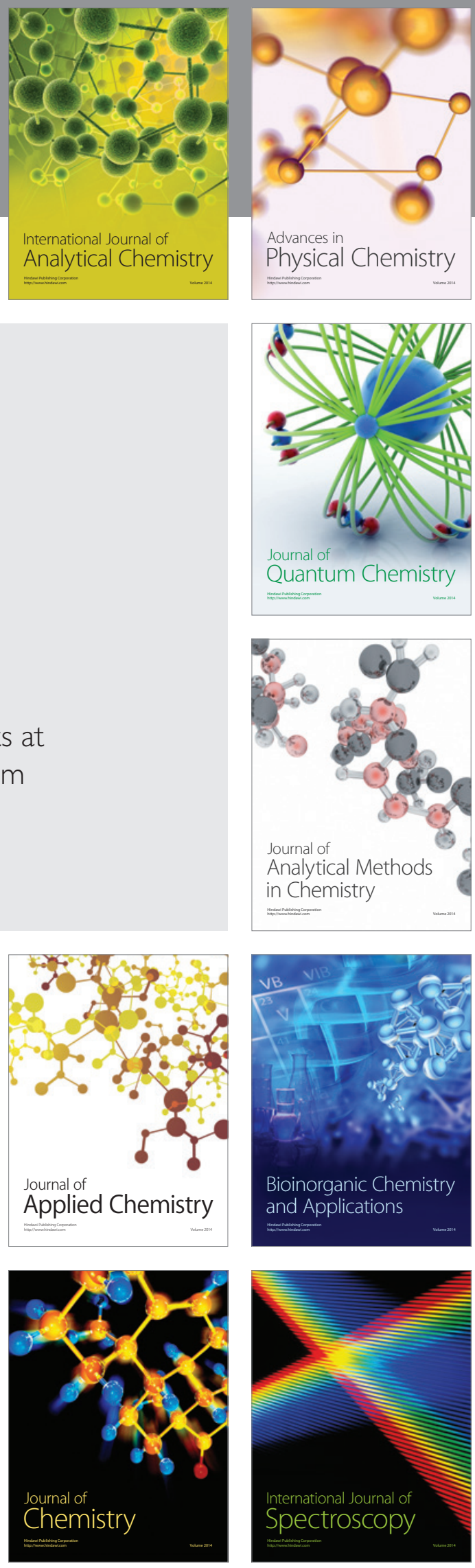